\title{
Evaluation of Diagnostic Radiography Technology Curriculum from the Graduates Perspective
}

\author{
Saeed M. Bafaraj ${ }^{*}$, Awad M. Elkhadir ${ }^{2}$ \\ ${ }^{1}$ Department of Diagnostic Radiology, Faculty of Applied Medical Sciences, King Abdulaziz University, Jeddah, KSA \\ ${ }^{2}$ Department of Diagnostic Radiology, Faculty of Applied Medical Sciences, King Abdulaziz University, Jeddah, KSA (Former) \\ Email: *smbafaraj@kau.edu.sa, awadkider@gmail.com
}

How to cite this paper: Bafaraj, S. M., \& Elkhadir, A. M. (2021). Evaluation of Diagnostic Radiography Technology Curriculum from the Graduates Perspective. Creative Education, 12, 265-277.

https://doi.org/10.4236/ce.2021.121019

Received: December 9, 2020

Accepted: January 26, 2021

Published: January 29, 2021

Copyright (C) 2021 by author(s) and Scientific Research Publishing Inc. This work is licensed under the Creative Commons Attribution International License (CC BY 4.0).

http://creativecommons.org/licenses/by/4.0/ cc (i) Open Access

\begin{abstract}
The purpose of this study is to evaluate the curriculum of diagnostic radiology technology for a bachelor degree considering the perspectives of graduates in Sudan. Exploring the graduate's perspective would help to know about rapid development required in the field of diagnostic radiography technology in this era, along with important suggestions for the curriculum development. The quantitative study designed is employed, and a survey of 139 Diagnostic Radiologic Technologists (DRTs) having up to date curriculum, was performed. The collected data have been evaluated using SPSS version 23.0. Descriptive and inferential statistics were computed for the collected data. The results of this investigation showed that more than half of the participants i.e., $54.7 \%$ said that curriculum which they had studied in BSc of radiography keeps pace with rapid development in the field. $26.6 \%$ of the respondents suggested that curriculum needs some review to increase training hours in modern imaging modalities such as Magnetic Resonance Imaging (MRI), Computed Tomography (CT) and Ultrasound (U/S). The study concludes that increasing the training time and integration of students when planning curriculum can improve students' competence in relation to diagnostic radiography technology. The integration of the curriculum review practices increases service quality to ensure safe practice.
\end{abstract}

\section{Keywords}

Diagnostic Radiography Technology, Diagnostic Radiologic Technologists, Graduates' Perspective, Radiography Curriculum, Training

\section{Introduction}

In the medical environment, the escalated technology has provided significant 
benefit to the patients, where the educational competence and training of the personnel act as the prime stimulators for quality care (Wang \& Kung, 2018). The growing role of radiographer for the interpretation of the images and its reporting is essential for the deliverance and expansion of the effectual clinical images in several countries, especially the developing one. Salih (2014) reports that the trends towards the development and extension of the radiographer are expanding in various countries such as Australia, United Kingdom (UK), USA and more. The reporting by the radiographer was recognized initially by the UK, which is in accordance with the statement forwarded by the British of Radiologists Council, which elucidated the role of radiographer for the radiographic image reporting (Snaith et al., 2015; Bornstein et al., 2014).

Reflecting upon the developing country, the radiography growth is also evident in the region of North Africa particularly Sudan which founded the first Diploma in Radiography in the region in 1932 (Salih, 2014). Due to its increasing popularity and growth, this soon became a bachelor's degree in 1995 (Elkhadir, 2015). The development in the radiography diagnosis indicated towards increasing the understanding of the students' as per the changes of the dynamic world. The use of ionizing radiation in Sudan has escalated based on its increasing use of the diagnostic $\mathrm{x}$-ray units and the medical practices (Khalfalla, 2011). Moreover, an earlier study by Amis et al. (2007) has also reported the increased utilization of high dose procedures in Sudan comprising of fluoroscopy, computed tomography (CT) scanning and interventional radiology (Image-guided techniques).

An important role is played by radiology technology in medical sciences as the students learn different imaging methods while using the systems in this curriculum (Alaamer, 2012). Initially, the designing of this curriculum was based on the aim to provide training to the technicians. However, later in 2007 this curriculum was improved to dissolute bachelors. Since then, the curriculum has not been reformed (Cunningham, Wright, \& Baird, 2015). The assessment of the literature provides that clinical education and curriculum followed in the radiology education are crucial for improving the students' skill set for meeting the required clinical demands (Baird, 2008). It is found that the formation of programs in consideration to the student's perspective allows better improvisation. This has been supported by Zwaan et al. (2017) which found that adequate descriptions involving the competency of the professional practice help students in assessing the requirements and fulfilling it with the understanding of professional knowledge. Evaluation of the literature provides that previously the conceptual aspects of the radiology have only been focused; whereas, the work in terms of education remains limited (Lundgren et al. 2015).

Therefore, the present study aims to evaluate the curriculum of diagnostic radiology technology for a bachelor degree considering the perspectives of graduates in Sudan. For this purpose, the opinions of Diagnostic Radiologic Technology Specialists' (DRTS) about the BSc curriculum are considered to explore if 
it keeps pace with rapid development or not and also get their important suggestions for the development of the curriculum. It is assumed that results of this study would assist in the formation of innovative formats which would further assist in the formation of a conducive environment and integrating value creation practices in the deliverance of radiography education.

\section{Literature Review}

Strong educational change in required in the education system to fulfil diverse educational needs of students, high student expectations, and increased demand of policy reports (Cheng, 1994). It is not possible to bring changes in the curriculum instantly, rather there is need to follow a continuous process for addressing the current situation in consultations and researches. Initially, there is need of identifying the significant challenges in curriculum being followed recently. A previous study by Lachiver and Tardif (2002) stated that there are 5 logical steps of managing change in curriculum. Those steps include; analyzing current context and offerings, expressing key program in mission statement, prioritizing development resources and strategies, implementing targeted curricula change, and establishing monitoring processes and tools. The approaches to bring about innovations in medical curriculum by producing medical professionals and radiologists, who can fulfill the healthcare requirements (Zabidi-Hussin, 2006). The innovations are likely to prepare students for providing health care facilities with basic focus on continued learning skills, assessing professionalism, emphasizing state of art clinical knowledge, and early clinical experience in the era of rapidly changing technology (Work et al. 2003). Transformation in medical curriculum ensures that students are prepared and adapted to challenges that would affect appropriate outcomes within the community, rather than just delivering competent students, academically.

In practices, diagnostic radiography is performed by the health care professional responsible for the conduction of medical imaging for diagnostic. Khalfalla (2011) stated that the use of the diagnostic radiography has enhanced the patients living in Sudan involving additional innovative modalities. The imaging procedure is performed by the Radiologic Technology Specialist (RTS) upon the request of and for interpretation by a radiologist or licensed practitioner (Abushab et al. 2018). Elkhadir and Saeed (2018) stated that the radiographic profession is undergoing various changes and developments which require devising of updated curriculum where the necessary competence can be developed among the practitioners.

According to Linaker (2015) the American Association of Dental Schools provided curricular guidelines in 1980 which specify the procedure and techniques to be followed in oral radiology. The use of the demonstrative technique has been found to improve students' learning competence. The timely and effective techniques for learning, teaching and evaluating have been stressed upon by The Society of Radiographers (Society of Radiographers, 2013). It stated that about 
50 percent of the clinical institutes which provide training do not specify the delivery mode. Zwaan et al. (2017) further add that the inefficiencies are observed in student's clinical performance when imaging is not indicated, such as they cannot determine whether the imaging technique is appropriate for a specific patient or not as well as its type.

The importance of radiology has increased in the recent time for correct and early diagnosis of many diseases (Præstholm, 1997). The establishment of first radiology curriculum was done in 1917 in USA (Nelhuebel, 2017). Education is considered as a process of facilitating learning by the teachers. Moreover, it can be defined as the planned activity between the student and the teacher to facilitate the process of learning (Saif, 2006). Curriculum based on modern medical education needs to be compatible based on a specific region, with a basic aim of improving the health services. Significant changes have been observed in different skills and knowledge, considering the advancements in technology. In this context, practical education is important for transmitting information, skills, and attitudes from one individual to another for altering proficiency and cognitive structures (Omar et al., 2009).

The main aim of medical education should be providing training to skillful health professional having enough knowledge, skill, and attitude to preserve and improve health. This highlights the significance of teaching and learning in the development of student's skills belonging to the field of medical sciences. A previous study has shown that different approaches should be used for conveying medical education and develop understanding about medical sciences that having significant impact on the knowledge and educational experiences of the professor (Karimi Moonaghi \& Binaghi, 2009). Optimal functions result due to lack of skills, abilities, knowledge, and accessibility to tools (Yarmohammadian et al., 2010). It is believed that there is increased reliance of optimal function on the skills and knowledge, regardless of the environmental conditions and personal information (Karimi Moonaghi \& Binaghi, 2009).

A previous study by Smith and Reeves (2009) stated that it is important for the radiographers to enhance their clinical expertise by altering the requirements of public expectation and health system. There is need to assimilate the ability of accessing and applying best clinical practice, efficiently into the practice of diagnostic radiography (Siddiqui et al. 2006). In the similar context, van Beek and Malone (2007) stated that the new information acquired in this era is likely to be applied towards radiographic expertise and patient care.

Another study by Hafslund et al. (2008) suggested that there is generation and use of day-to-day service delivery is possible by diagnostic radiographers, despite of their qualification.

According to Ludmerer (2010), the main components of Flexner's report including; rigorous entrance requirement, learning by performing, medical positivism, and scientific method are likely to provide paradigm shift from student towards a passive learner. The above justifications clearly stated that there is 
need to place strong emphasis on the individuality of students so that they are able to get molded into independent active responsible adult learners in program.

\section{Material and Methods}

\section{Study Design}

For evaluating the diagnostic radiography technology curriculum from the graduates' perspective, a cross-sectional study design has been employed. This is likely to provide close-detail analysis, along with significant observations to build specific theories that hold and guarantee the quality of data collected. In it, the quantitative approach is applied based on its effectual and effective procedure for collecting valuable data. Moreover, it also assists in enlightening more opportunities for obtaining valuable insights and perspectives on the concerned subject matter of the study.

\section{Study Participants}

A total of 139 individuals were recruited through randomized sampling technique. The study sample was derived from a population of DRTs (Diagnostic Radiologic Technologist) in Sudan. The researcher visited the group of DRTs practicing at two different organizations. It was assured that the participants had learnt to manipulate diagnostic X-ray equipment and the technical factors affecting X-ray images. Moreover, they had participated in a minimum of 12 credit hours of clinical study.

\section{Ethical Consideration}

Ethical approval was granted by the governing institution of the researcher to recruit participants and execute the study. These conditions were strictly followed for all activities relating to data collection, handling, and dissemination. On the account of potential identifiability within a professional community, the conditions stated for ethical approval delimit any further elucidation of participant demographics.

\section{Data Collection}

The study has performed a survey for the collection of data. For this, a close-ended questionnaire was used, which initially gather demographic details such as graduation year and experience followed by questions centered on the diagnostic radiography technology curriculum. It also included questions related to exclusive courses and skills, along with the impact of on the capability of solving different problems encountered during work. The questionnaire was based on current literature and the practical experience of the author. Alpha Cronbach coefficient was used to assess the validity and compatibility of the questionnaire. The value of alpha Cronbach coefficient for this study came out to be was 0.72 , which was acceptable.

Prior to the distribution of the questionnaire through email, the permission was acquired from the relevant authorities, where a brief description was provided to the participant along with the provision of the consent form to the participants demonstrating their willingness for participation. The participants were also ensured of the confidentiality and anonymity in the study. 


\section{Data Analysis}

The collected data was analyzed using statistical package for social sciences (SPSS) version 23.0. The descriptive and inferential statistics were calculated for evaluating the graduates' perspective on the diagnostic radiography technology curriculum.

\section{Results}

Table 1 presents the demographics of the contacted DRTs. Based on the responses provided, it is found that $38.8 \%$ of the participants graduated in the year from 2014-2009. Reflecting upon the years of experience, most of the participants i.e., $47.5 \%$ had 1 to 5 years of experience, $13.7 \%$ had 10 to 15 years of experience, followed by $11.5 \%$ of participants possessing 15 to 20 years of experience.

Assessment of participants' opinion of curriculum development in relation to technological development is exhibited in Table 2. According to responses, $54.7 \%$ agree that it is parallel to the rapid development which is taking place, whereas 43.9 responded negatively.

The evaluation of the participant suggestion has been indicated in Table 3 pertaining to the curriculum, where most of the participant (26.6) emphasized for the review of the curriculum.

Table 1. Demographic profile of the participants.

\begin{tabular}{cccc}
\hline Variables & & N & $\%$ \\
\hline $2014-2009$ & 54 & 38.8 \\
$2008-2003$ & 24 & 17.3 \\
Graduation Year & $2002-1997$ & 25 & 18.0 \\
& $1996-1991$ & 12 & 8.6 \\
$1990-1985$ & 8 & 5.8 \\
$1984-1979$ & 6 & 4.3 \\
\hline \multirow{3}{*}{ Experience Years } & 5 to 5 & 66 & 47.5 \\
& 10 to 15 & 14 & 10.1 \\
& 15 to 20 & 19 & 13.7 \\
20 to 25 & 16 & 11.5 \\
& More than 25 years & 6 & 5.8 \\
& No comment & 10 & 4.3 \\
\hline
\end{tabular}

Table 2. Opinion of participants about curriculum development.

\begin{tabular}{|c|c|c|c|}
\hline \multicolumn{2}{|c|}{ Variables } & \multirow{2}{*}{$\begin{array}{l}\mathbf{N} \\
76\end{array}$} & \multirow{2}{*}{$\begin{array}{c}\% \\
54.7\end{array}$} \\
\hline & Yes & & \\
\hline \multirow[t]{2}{*}{ Opinions } & No & 61 & 43.9 \\
\hline & No Comment & 2 & 1.4 \\
\hline
\end{tabular}


Table 3. Suggestion provided by participants related to radiography technology curriculum.

\begin{tabular}{lllc}
\hline Variables & N & $\%$ \\
\hline \multirow{3}{*}{ Suggestion } & Review Curriculum & 37 & 26.6 \\
& More Radiographic Pathology & 14 & 10.1 \\
& Add Advanced Imaging Modalities & 10 & 7.2 \\
& No Comment & 4 & 2.9 \\
& Missing & 74 & 53.2 \\
\hline
\end{tabular}

Table 4. Participants opinion about the clinical practice of the BSc curriculum.

\begin{tabular}{lcccc}
\hline \multicolumn{2}{c}{ Variables } & & N & \% \\
\hline \multirow{3}{*}{ Opinions } & Yes & 76 & 54.7 \\
& No & 57 & 41.0 \\
& No Comment & 6 & 4.3 \\
\hline
\end{tabular}

Table 5. Suggestions for Clinical Practice of the BSc Curriculum

\begin{tabular}{llcc}
\hline \multicolumn{1}{c}{ Variables } & N & $\%$ \\
\hline \multirow{5}{*}{ Suggestion } & Increase Training Hours in Imaging Modalities & 49 & 35.3 \\
& Start Practical From $1^{\text {st }}$ Year & 2 & 1.4 \\
& Availability of Advance Training Center in Faculty & 2 & 1.4 \\
& Follow Up by Clinical Instructor & 2 & 1.4 \\
& No Comment & 6 & 4.3 \\
& Missing & 78 & 56.1 \\
\hline
\end{tabular}

Table 4 exhibits the opinion about the clinical practice of the BSc curriculum which the participants studied. Based on the responses, it is revealed that a significant portion of the sample i.e., $54.7 \%$ agrees its correspondence to the achievement of the set objective.

Table 5 represents that many participants suggested for increasing the training hours in the imaging modalities.

\section{Discussion}

The evaluation of the diagnostic radiography technology curriculum from the graduate's perspective is found to be beneficial. Based on the findings, the curriculum effectiveness of radiology education is indicated in the educational institutes of Sudan. This is in-line with the study findings of Elkhadir (2015) which indicated towards the integration of the modern systematic educational strategies among the radiologic technology institutes in Sudan. The formation of the curriculum in relation to the suggestion of graduates is also indicated by Jagersma (2010). Improved process of curriculum planning is also supported by Ostojić et al. (2015) which reported the enhancement of educational programs based on the students' generated insights. 
The present study showed that radiographic pathology was suggested by $10.1 \%$ participants, which was followed by $7.2 \%$ suggesting integration of advanced imaging modalities. However, this was left unattended by a significant percentage i.e., $53.2 \%$. Considering these results, it can be stated that the education curriculum among the students as the strategy for escalating the curriculum effectiveness (Meyer, 2018; Uljens, 2015). The effectiveness of the review of the curriculum is also stated by Santos et al. (2016) which assessed the oral radiology education systematically. It is suggested that the curriculum review integrating technology such as online tools supplementing traditional teaching and learning strategies improves students' competence. This is also endorsed by Jabbari et al. (2012) who supported the evaluation of the students' opinion for assessing the effectiveness of the educational curriculum as used in the present study.

According to the present study, equal suggestions were provided for practicing from $1^{\text {st }}$ year, the establishment of the advanced training center in faculty, and follow up by clinical instructor (1.4\%). The current findings also reveal the effectiveness of the radiology-pathology in improving the curriculum for radiology education (Young \& Siordia, 2012). This is parallel to the findings of Chapiro et al. (2014) which conducted a radiologic-pathologic analysis on patients experiencing HCC. Similarly, the effectiveness of the radiology-pathology is also supplemented by the study of Stomatology (2014), which used the radiographic techniques in the implant dentistry.

According to the present study, equal suggestions were provided for practicing from $1^{\text {st }}$ year, the establishment of the advanced training center in faculty, and follow up by clinical instructor (1.4\%). There was no comment suggested by $4.3 \%$ of the respondents; while, it remained empty by the $56 \%$ participants. These findings clearly suggest the increased use of training for improving the clinical practice. Similarly, the presents study findings are corroborated by Asare (2017) showing that the integration of the students in the clinical setting allows them to become more competent, and collaborative. Moscova et al. (2015) also indicated that increase training hours in imaging modalities improves the radiologist skills. The increased training hours in modern imaging modalities such as MRI, CT and U/S are also said to improve the training.

There are certain shortcomings observed in the study which can be overcome by the future researches. Such as the study was limited to the region of Sudan, which limits its results generalizability to other regions based on its divergent socio, economic and political conditions. Along with it, the time duration and study sample can also be improved for gathering better results. Additionally, the perception of the teachers and curriculum planners can also be assessed by future researches which may assist in expanding the knowledge of the radiography education.

\section{Conclusion}

The study assessed the students' perception of evaluating their opinion in 
relation to the diagnostic radiography technology curriculum. Overall results of the study indicated that curriculum research is crucial for advancing the educational process irrespective of its scope whether small or large. Use of curriculum is helpful in gathering relevant insights and molding the educational practice for strengthening the curriculum. The results of the study emphasized the integration of the curriculum review practices; whereas, improving training hours for training to increase service quality and to ensure safe practice.

\section{Recommendations}

The results of present study clearly recommend that there is need of developing practical courses for the students for increasing their familiarity with professional environment that further leads to achieving more skills. Therefore, it is believed that education program for the radiography must base its curriculum parallel to the findings and development taking place at national and international level. Along with it, the current practices of the clinical practitioner must also be researched for improving the practical competence of the graduates, which leverages their professional growth and increases cooperation among the users. The program curriculum is also suggested to be based on the practices of the professionals, who are aware of the challenges which they endure, assisting in devising effective practicality-based curriculum. Additionally, the collaboration between the clinical and educational institutes is recommended to ensure that the best practices are adopted for meeting the students' needs.

Moreover, it is also recommended to use cross-sectional imaging and flexible study pathways in the new curricula by considering the available clinical education resources. The graduates need to be resilient and possess realistic expectation regarding their career to combat increased pressures and alteration in working practices. This required graduates, who are highly professional, motivated, and possess well-developed communicating skills. The results clearly demonstrated that there is need to focus on the actual role of a radiologic technologist for the expected competency required in the radiography graduate of future.

\section{Ethical Approval}

Prior to the distribution of the questionnaire, the permission was acquired from the relevant authorities.

\section{Consent to Participate}

Verbal consent was obtained from the participants and they were also ensured of the confidentiality and anonymity in the study.

\section{Consent for Publication}

Not applicable. 


\section{Availability of Data and Materials}

The datasets used and analyzed during the current study are available from the corresponding author on reasonable request.

\section{Funding}

This research did not receive any specific grant from funding agencies in the public, commercial, or not-for-profit sectors.

\section{Acknowledgements}

The author is thankful to all the associated personnel, who contributed to this study by any means.

\section{Conflicts of Interest}

The authors declare no conflicts of interest regarding the publication of this paper.

\section{References}

Abushab, K. M., Suleiman, M. D., Alajerami, Y. S. M., Alagha, S. I., ALnahal, M., Najim, A., \& Naser, M. (2018). Evaluation of Advanced Medical Imaging Services at Governmental Hospitals-Gaza Governorates, Palestine. Journal of Radiation Research and Applied Sciences, 11, 43-48. https://doi.org/10.1016/j.jrras.2017.10.007

Alaamer, A. S. (2012). Radiography Education and Training in Saudi Arabia. Open Journal of Radiology, 2, 134-140. http://dx.doi.org/10.4236/ojrad.2012.24025

Amis Jr., E. S., Butler, P. F., Applegate, K. E., Birnbaum, S. B., Brateman, L. F., Hevezi, J. M. et al. (2007). American College of Radiology White Paper on Radiation Dose in Medicine. Journal of the American College of Radiology, 4, 272-284. https://doi.org/10.1016/j.jacr.2007.03.002

Asare, H. K. (2017). Student Radiographers' Perceptions of Clinical Placement: A Survey in Ghana. Journal of Radiology \& Radiation Therapy, 5, Article No. 1075.

Baird, M. A. (2008). Towards the Development of a Reflective Radiographer: Challenges and Constraints. Biomedical Imaging and Intervention Journal, 4, e9.

Bornstein, M. M., Al-Nawas, B., Kuchler, U., \& Tahmaseb, A. (2014). Consensus Statements and Recommended Clinical Procedures Regarding Contemporary Surgical and Radiographic Techniques in Implant Dentistry. The International Journal of Oral \& Maxillofacial Implants, 29, 78-82. https://doi.org/10.11607/jomi.2013.g1

Chapiro, J., Wood, L. D., Lin, M., Duran, R., Cornish, T., Lesage, D., \& Savic, L. J. (2014). Radiologic-Pathologic Analysis of Contrast-Enhanced and Diffusion-Weighted MR Imaging in Patients with HCC after TACE: Diagnostic Accuracy of 3D Quantitative Image Analysis. Radiology, 273, 746-758. https://doi.org/10.1148/radiol.14140033

Cheng, Y. C. (1994). Effectiveness of Curriculum Change in School. International Journal of Educational Management, 8, 26-34. https://doi.org/10.1108/09513549410062416

Cunningham, J., Wright, C., \& Baird, M. (2015). Managing Clinical Education through Understanding Key Principles. Radiologic Technology, 86, 257-273.

Elkhadir, A. M. (2015). Evaluation of BSc Radiologic Sciences and Medical Imaging Technology Programmes in Sudanese Universities from Students' Perspective. Open 
Journal of Radiology, 5, 205-211. http://dx.doi.org/10.4236/ojrad.2015.54028

Elkhadir, A. M., \& Saeed, I. O. (2018). Sudanese Radiologic Technology Specialist Embrace A Challenge: Focus on Image Interpretation-A Survey Study. International Journal of Radiology, 5, 144-148. https://doi.org/10.17554/j.issn.2313-3406.2018.05.48

Hafslund, B., Clare, J., Graverholt, B., \& Nortvedt, M. W. (2008). Evidence-Based Radiography. Radiography, 14, 343-348. https://doi.org/10.1016/j.radi.2008.01.003

Jabbari, N., Zeinali, A., \& Ageshteh, S. (2012). Assessment of Radiology Technology Students' Internship with Objective Structured Clinical Examination. Future of Medical Education Journal, 2, 19-23. https://dx.doi.org/10.22038/fmej.2012.344

Jagersma, J. (2010). Empowering Students as Active Participants in Curriculum Design and Implementation. https://files.eric.ed.gov/fulltext/ED514196.pdf

Karimi Moonaghi, H., \& Binaghi, T. (2009). Teaching and Learning Style and the Application in Higher Education. Mashhad: Mashhad University of Medical Sciences.

Khalfalla, R. G. I. (2011). Radiological Examination Frequency and Collective Effective Doses from Interventional Radiology Procedures in Sudan. Doctoral Dissertation, Khartoum: University of Khartoum.

Lachiver, G., \& Tardif, J. (2002). Fostering and Managing Curriculum Change and Innovation. 32nd Annual Frontiers in Education, Boston, 6-9 November 2002, F2F-F2F. https://doi.org/10.1109/FIE.2002.1158168

Linaker, K. L. (2015). Radiology Undergraduate and Resident Curricula: A Narrative Review of the Literature. Journal of Chiropractic Humanities, 22, 1-8.

https://doi.org/10.1016/j.echu.2015.09.004

Ludmerer, K. M. (2010). Commentary: Understanding the Flexner Report. Academic Medicine, 85, 193-196. https://doi.org/10.1097/ACM.0b013e3181c8f1e7

Lundgren, S. M., Lundén, M., \& Andersson, B. T. (2015). Radiography-How do Students Understand the Concept of Radiography? Radiography, 21, e68-e73. https://doi.org/10.1016/j.radi.2015.01.005

Meyer, M. (2018). The Relationship between Core Knowledge Sequence Curriculum and Smarter Balance Assessment English Language Arts Scores. https://digitalcommons.georgefox.edu/cgi/viewcontent.cgi?article $=1119 \&$ context $=$ edd

Moscova, M., Bryce, D. A., Sindhusake, D., \& Young, N. (2015). Integration of Medical Imaging Including Ultrasound into a New Clinical Anatomy Curriculum. Anatomical Sciences Education, 8, 205-220. https://doi.org/10.1002/ase.1481

Nelhuebel, R. M. (2017). Incorporation of General Education in Radiography Program Curricula: A Basic Qualitative Study. Doctoral Dissertation, Capella Tower, MN: Capella University.

Omar, M., Gerein, N., Tarin, E., Butcher, C., Pearson, S., \& Heidari, G. (2009). Training Evaluation: A Case Study of Training Iranian Health Managers. Human resources for Health, 7, Article No. 20. https://doi.org/10.1186/1478-4491-7-20 http://www.human-resources-health.com/content/7/1/20

Ostojić, G., Jovanović, V., Kozak, D., Ivandić, Z., \& Stankovski, S. (2015). Mechatronic Education at the Faculty of Technical Sciences Novi Sad. Tehnicki Vjesnik, 22, 805-812. https://doi.org/10.17559/TV-20140225111636

Præstholm, J. (1997). The Origin and Development of Diagnostic Radiology as Illustrated by Postage Stamps. Acta Radiologica, 38, 930-936. https://doi.org/10.1080/02841859709172105

Saif, A. A. (2006). Educational Psychology (Psychology of Learning and Teaching). Te- 
hran: Doran.

Salih, S. (2014). Comparison of Nuclear Medicine Radiographer and Nuclear Medicine Physician Reporting on 99mTc Pertechnetate Thyroid Scans: An Experience from Sudan. Journal of American Science, 10, 121-124.

Santos, G. N. M., Leite, A. F., Figueiredo, P. T. D. S., Pimentel, N. M., Flores-Mir, C., de Melo, N. S. et al. (2016). Effectiveness of E-Learning in Oral Radiology Education: A Systematic Review. Journal of Dental Education, 80, 1126-1139. https://doi.org/10.1002/j.0022-0337.2016.80.9.tb06195.x

Siddiqui, K. M., Weiss, D. L., Dunne, A. P., \& Branstetter, B. F. (2006). Integrating Imaging Informatics into the Radiology Residency Curriculum: Rationale and Example Curriculum. Journal of the American College of Radiology, 3, 52-57. https://doi.org/10.1016/j.jacr.2005.08.016

Smith, S., \& Reeves, P. (2009). The Extension of the Role of the Diagnostic Radiographer in the UK National Health Service over the Period 1995-2009. European Journal of Radiography, 1, 108-114. https://doi.org/10.1016/j.ejradi.2010.08.003

Snaith, B., Hardy, M., \& Lewis, E. F. (2015). Radiographer Reporting in the UK: A Longitudinal Analysis. Radiography, 21, 119-123. https://doi.org/10.1016/j.radi.2014.10.001

Society of Radiographers (2013). Scope of Practice 2013. http://www.sor.org/learning/document-library/scope-practice-2013. 2013.

Uljens, M. (2015). Curriculum Work as Educational Leadership-Paradoxes and Theoretical Foundations. Nordic Journal of Studies in Educational Policy, 2015, Article No. 27010. https://doi.org/10.3402/nstep.v1.27010

van Beek, E. J., \& Malone, D. E. (2007). Evidence-Based Practice in Radiology Education: Why and How Should We Teach It? Radiology, 243, 633-640. https://doi.org/10.1148/radiol.2433051098

Wang, Y., Kung, L., \& Byrd, T. A. (2018). Big Data Analytics: Understanding Its Capabilities and Potential Benefits for Healthcare Organizations. Technological Forecasting and Social Change, 126, 3-13. https://doi.org/10.1016/j.techfore.2015.12.019

Work, J. A., Wagner, P. J., Albritton, T. A., White, C., Thomas, A., \& Fincher, R. M. E. (2003). Innovations in Medical Education: The Medical College of Georgia School of Medicine Experience. Southern Medical Journal, 96, 840-844.

Yarmohammadian MH, Bahrami S, Foroughi Abari AA. (2010). Educational Administration and Planning. Isfahan: Isfahan University of Medical Sciences Publications, Persian.

Young, K. J., \& Siordia, L. (2012). Teaching, Leadership, Scholarly Productivity, and Level of Activity in the Chiropractic Profession: A Study of Graduates of the Los Angeles College of Chiropractic Radiology Residency Program. Journal of Chiropractic Humanities, 19, 12-23. https://doi.org/10.1016/j.echu.2012.10.002

Zabidi-Hussin, Z. A. M. H. (2006). Curricular Trends in Malaysian Medical Schools: Innovations Within. Annals, Academy of Medicine, Singapore, 35, 647-654. https://www.annals.edu.sg/pdf/35VolNo9Sep2006/V35N9p647.pdf

Zwaan, L., Kok, E. M., \& Van Der Gijp, A. (2017). Radiology Education: A Radiology Curriculum for All Medical Students? Diagnosis, 4, 185-189.

https://doi.org/10.1515/dx-2017-0009 


\section{Abbreviations}

DRT Diagnostic Radiologic Technologists

MRI Magnetic Resonance Imaging

CT Computed Tomography

U/S Ultrasound

UK United Kingdom

RTS Radiologic Technology Specialist

DRTS Diagnostic Radiologic Technology Specialists 